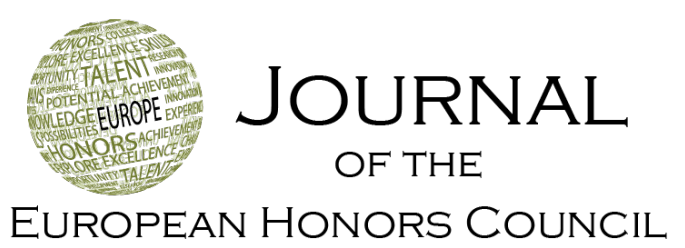

Note

\title{
Introduction to the special issue: Honors education in the digital age
}

\author{
Beata Jones ${ }^{1}$ and Maarten Hogenstijn ${ }^{2}$
}

1. Guest Editor Special Issue; Texas Christian University, USA

2. Coordinating Editor; European Honors Council Secretary; Hanze University of Applied Sciences, The Netherlands

Correspondence: journal@honorscouncil.eu

Published: 22 September 2020

\section{Introduction}

The Editorial Board is honored to present a new special issue of the Journal of the European Honors Council (JEHC), focused on Honors Education in the Digital Age. When this special issue was planned in mid-2019, we could not have imagined that, at the time of publication almost all education around the world would have been digitalized, following the COVID-19 pandemic that started to spread around the world in the first months of 2020. Education, including honors education, was forced to enter the digital age almost overnight.

At the start of the pandemic, the deadline for the special issue had passed and contributions were already being processed. However, following these developments, in April of 2020, the special issue was briefly reopened for new contributions related to the COVID-19 crisis. We now present a special issue section combining five original contributions and five new COVID-19-related contributions. Aditionally, we also publish two other contributions which are not specifically related to the theme of the digital age but are relevant for the development of honors education around the world. All contributions form an issue which emits a high sense of urgency.

\section{Contributions originally received for the special issue}

The contributions originally received for the special issue share a practical approach towards dealing with the reality of the digital age we have entered. We open the special issue with a paper on the professional competencies needed to thrive in the new economy that has undergone a Fourth Industrial Revolution. In "The W-shaped professional competencies model for the Fourth Industrial Revolution and its relevance to honors programs," Beata Jones (USA), and Albert Pilot, Pierre van Eijl, and Josephine Lappia (Netherlands) propose the W-shaped professional competencies model, which is focused on human literacy, digital 
fluency, hyper-learning, and systems and design thinking competencies. The paper can be read as a call to action for university administrators and teachers to rethink their approach to the skills they focus on in their teaching to make education more relevant for the current digital age.

In his note "Academic skills in the screenish era," Peter Bradley (USA) also focuses on skills. Now that we have moved from a "bookish" to a "screenish" era, a change is needed in the academic skills required and taught. Bradley argues that we must "use the honors tradition of allowing our students to shape their education to create a system of education for the future, not the past."

But how can such education for the future practically take shape? In their paper, "The digital common read: Creating a space for authentic engagement with social annotation," Matthew Wranovix and Mary Isbell (USA) provide an example. They describe their experience in using a system of digital annotation of literature to create an online space where incoming firstyear students can engage with each others' ideas and get a social and intellectual experience before arriving on campus.

Moving to the organizational side of education, many honors programs and colleges need to raise funds. In the note "(Fund)raising honors: Blending conventional and technological approaches to development," Rebecca Bott-Knutson, Hanna Holmquist, and Keith Mahlum (USA) share their approach to the fundraising issue in the digital age, combining conventional approaches with the use of digital platforms. The focus is always on raising honors, by using a strategy of raising the bar, raising awareness, and raising relationships.

Finally, some more food for thought is provided by a review of Robot-proof: Higher education in the age of artificial intelligence (by Joseph E. Aoun). Reviewer Albert Pilot discusses Aoun's innovative concept of "Humanics" as a discipline that teaches both mastery of professional knowledge and the development of technological literacy, data literacy, and human literacy. He suggests that honors programs can serve as a laboratory for the new forms of education suggested by Aoun.

\section{Handling COVID-19 implications and the digitalization of education}

The second part of this special issue includes five contributions directly related to the effects of the COVID-19 pandemic. These contributions are focused on showing practical ways to handle the challenges of the sudden digitalization of university education. In the note "Honors in the Time of Corona," John Zubizarreta (USA) presents and discusses a highly useful collection of international resources on four topics: retooling faculty approaches to teaching; addressing student access and success; adapting capstone projects and presentations to online delivery and assessment; and adjusting grades.

A specific challenge for honors education in times of lockdown and restrictions on physical meetings is how to create and maintain a sense of community. In the note "Creating community during the COVID-19 pandemic: Honors makes a case online," Marca Wolfensberger and Marte Vroom (Netherlands) present the approach taken by the honors program they are involved in as a coordinator and a student. The focus is on wellbeing and community, creating a series of online meetings where movies, TV series, or books are 
discussed, but where there is also room to share experiences during the pandemic. The honors students organize these meetings themselves and feel empowered by the opportunity to do so.

The paper "Assessment of the impact of COVID-19 on honors student learning, institutional connections, and intent to return to campus" by Evren Celik Wiltse, Michael Gonda, Camille Massmann, Kas Williams, and Rebecca Bott-Knutson (USA) reports on quantitative and qualitative research among honors and non-honors students on the impact of the pandemic. A lot of students struggle after the transition to an online environment and the need for improved communication is clear. Honors students, though, report fewer technology barriers and financial stressors than non-honors students. Degree completion and social connections are driving students' desire to return to face-to-face classes.

Shifting focus from students to staff, John Zubizarreta and Beata Jones (USA) and Marca Wolfensberger (Netherlands) discuss experiences in building an online occasion for professional development in the note "Honors International Faculty Learning Online (HIFLO 2020): A model for honors online professional development." The authors delivered two online seminars focused on "Creating Community-Experiences from Honors" and "Remote Honors-Teaching for Deep Virtual Learning," respectively. Eleven lessons learned in preparing and executing these seminars are shared, aiming to inspire others to engage in similar endeavors.

In the note "Remote teaching transition during COVID-19 - the first five weeks and the start of a digital knowledge-building community," Marca Wolfensberger \& Ning Ding (Netherlands) return to the reality of the first few weeks during the pandemic. A digital knowledge-building community gradually emerged after initial experimentation by individual teachers to find suitable digital forms to deliver content, to keep communicating with students and colleagues, and to assess learning outcomes. Even in these first few weeks, a need for new pedagogies already became apparent, but time was lacking to rethink approaches. Moving into a new phase of the COVID-19 crisis, these lessons from the first few weeks should not be forgotten.

\section{Other contributions}

As the final treat in this issue, we present two highly relevant contributions not directly related to the topic of the digital age. In the first note in JEHC to come from Russia, Maria Tarasova presents "Highlights of the 2019 honors session at the International Students' Conference in Siberian Federal University, Russia." Tarasova also takes the opportunity to briefly introduce the program at her university, which was started in 2017 . While this note was not submitted to be a part of the special issue, it does contain an interesting section on the use of gamification.

Finally, we return to the topic of competencies in the paper "Relevance and meaningfulness: Student perspectives on the highly talented international business professional profile" by Petra van Heugten, Marjolein Heijne-Penninga, Patricia Robbe, Debbie Jaarsma, and Marca Wolfensberger (Netherlands). The authors discuss the talent competency framework that was developed for highly talented international business professionals and then focus on honors students' perspectives on this profile. Which elements do they experience as 
relevant and meaningful, and how do they perceive working with it? Results suggest that relevance and meaningfulness can be improved through better alignment between educators and the professional field.

\section{Final remarks}

$J E H C$ 's general aim is to share knowledge and good practices regarding honors programs and talent development programs in higher education. Education has entered the digital age, and the COVID-19 pandemic has further highlighted the urgent need to deal with this transformation, whether we like it or not. This special issue provides research results, models, reflections, and examples that may help educators respond to the challenges they are currently facing, as well as those that lie further ahead.

$J E H C$ will continue to publish contributions on research into honors and talent development in higher education. The Editorial Board invites you to contribute to the next issue(s) of the journal by sending in your papers and notes. All information on contributing can be found on the website www.jehc.eu.

\section{Acknowledgments}

The Editorial Board would like to thank Saffyre Falkenberg at Texas Christian University (USA) for copyediting and Hanze University of Applied Sciences Groningen (the Netherlands) for supporting the hosting of the journal. 